\title{
浅析中国古代书法教育
}

周晴

河北美术学院

DOI:10.32629/er.v3i2.2474

[摘 要] 汉字贯穿古今, 是中华五千年文明屹立世界的顶梁柱, 汉字之所以得以传承离不开中国古代书法教育的传承, 本文就古代书法教育的形 式、以及教育特点进行浅析,也为现代书法教育提供一些思考。

[关键词] 蒙学; 书法教育; 传承

教育乃立国之本, 中华文明也正是在教育中得以传承。在中国古代教 育中, 对于书法的教育是重中之重, 各个时期的统治阶级也都对书法教育 有着不同程度的重视。随着时代的发展, 以及统治阶级对于书法的重视程 度的不同、教育方式的不同使得书法的形式、分类丰富, 风格多样。我就 不同时期的书法教育方式的不同将古代书法教育分为了三个时期：萌芽 期、转折期和成熟期。

\section{1 萌芽期}

商代甲骨文的出现, 开启了中国汉字的篇章, 随着汉字的出现, 随之而 来的就是对于汉字的传承, 这也形成了最初的书法教育的萌芽。商代甲骨 文主要的作用是用来占卜、祭祀之用, 从出土的甲骨文中发现有一片甲骨 所刻的五行干支中, 一行工整、有力, 其余四行歪斜凌乱。由此推断第一行 为老师所刻, 其余四行为初学者所刻。在郭沫若先生的《殷器粹编》中对 第 “一四六五” 片考释云:

“此干支之残, 字甚恶劣, 如初学涂鸦者然” [1]

由此可以推断出, 当时的书法教学十分现实, 就是针对实际用途进行 教学。

西周时期, 出现了 “国” 的概念, 将天子所居住的都城连同四郊六 乡的范围称之为 “国” 在国内开设了小学, 而王公贵族设有国学, 包括 了大学和小学, 并且有了一定的选官制度。其教学内容在《周礼・保氏》 中记载:

养国子以道, 乃教之六艺: 一曰五礼, 二曰六乐, 三曰五射, 四曰五驭, 五曰六书, 六曰九数…… ${ }^{[2]}$ 。

其中 “六书” 指的就是书法, 可见当时书法教育已经作为了一项重 要的教学内容。当时所用的教材主要是《史䉪篇》此书也是第一次对文 字系统的整理, 使得识字与练字有了固定的教材。书法教育从此正式的 形成。

春秋战国时期, 不同思想的碰撞, 百家争鸣的出现, 使得原有的教育制 度遭到破坏, 私学开始兴起。不同国家的建立文字也随之变得更加多元化, 加之各大家之间更加注重思想的碰撞, 书法教育的地位大不如前, 只作为 辅助教学的作用出现。

秦始皇统一中国, 封建制度开启, 提出了 “车同轨、书同文” 统一了文 字一一小管。为了提高自己对全国的统治, 秦始皇将《仓颕篇》《爱历篇》 和《博学篇》作为了识字与书法教育的范本, 以此来推行小管。从此, 书法 教育在古代教育中有了自己举足轻重的地位。

\section{2 转折期}

两汉时期随着朝代的更替, 现实的需要, 小䇡逐渐推出了历史舞台, 隶 书兴起, 成为了书法史上的重要转折点, 西汉时期的字虽未完全脱离管字 但字形、笔画已经发生了巨变。与此同时,书法教育也在发生着巨变。

变化一：教材之变。西汉时随着汉隶、章草的兴起与广泛使用, 秦代
所用的《仓颕篇》、《爰历篇》、《博学篇》等专属教材退出了书法教学, 取 而代之的是将《仓颕篇》、《爱历篇》、《博学篇》整合成一本《仓颕篇》, 分为上中下三册, 随后又出现了司马相如《凡将篇》来补充《仓颉篇》中 所没有的字, 后有《急就篇》、《训纂篇》等教材不断充实。尤其是东汉时 期的《喜平石经》的刻制不仅巩固了儒学的地位, 同时也成为了一本教育 范本, 对学童写字的规范性上起到了重要作用。

变化二：学制之变。在西汉之前, 虽已在蒙学开设书法教育但未对 年龄、书写程度有所规定。而自西汉起, 统治者十分重视书学教育, 对学 童的年龄、考核都有了明确的规定, 并且有书法特长可以成为选官入仕 的捷径。

在汉代蒙学教育中书法教育也是有着举足轻重的地位的, 在王充《论 衡・自记篇》:

六岁教书……八岁出于书馆。书馆小童百人以上, 或以书丑得鞭。充 书日进, 手书即成, 辞师受《论语》《尚书》 ${ }^{[3]}$ 。

由此可以看出两汉时期蒙学教育中书法的地位。

书法特长对于选官而言两汉更是有了法律的规定。在《尉律》中规定： 学童十七以上始试, 讽籀书九千字, 乃得为史。又以八体试之, 郡移太 史并课, 最者以为尚书、史。书或不正, 辄举劾之。

由此我们可以看出书法在学子应试中的重要地位。在东汉时期, 更是 在官吏考察中将 “能书” 作为考察的一个重要条件。因此一些小吏也是一 有闲暇就练习书法。

变化三: 多种教学模式兴起。在汉代以前, 教学模式相对来说较为 单一, 某个时代只有单一的一种教学模式存在, 例如: 在西周, 主要以官 学为主, 私学相对而言较少; 到了春秋战国, 受当时时代的影响, 私学兴 起, 而官学又变的相对薄弱; 到了秦朝, 秦始皇焚书坑儒, 杜绝一切私学, 这一政策使得私学销声匿迹。而到了西汉初期, 因为统治阶级信奉黄老 之学, 在相对宽松的政策下加之官学并不发到, 私学再次兴起。汉武帝时 提出了 “罢黜百家独尊儒术” 思想, 从此在中国历史上将儒家思想推上 了高峰。加之汉武帝将官学推广到全国, 此时官学兴盛同时, 因此私学与 官学都在此时得到了良好的发展。与此同时, 书法随着地位的提高, 书法 家也越来越多, 因此, 书法的家学也逐渐兴起, 也一直延续到后代, 并产 生了深远的影响。

变化四: 鸿都门学的设置。鸿都门学是中国历史上第一所文学艺术专 科大学。汉灵帝是一位在政治上没有什么建树但是却很有才华的皇帝, 鸿 都门学的设立使得书法不再只是单一的学科, 而是确立了书法的艺术地位, 人们将书法作为了一项艺术来欣赏和研究。它的设立为中国培养了大量的 书法人才, 也在很大程度推进了书法的发展。

正是因为两汉时期的统治阶级对书法的重视, 所以使得这一时期的书 法得到了长足的发展, 也成为了中国书法历史的一个重要转折点。 


\section{3 成熟期}

书法自两汉时期起成为了每个学子的必修课, 也一直延续的后代, 书 法教育也更加的完善和成熟。

魏晋南北朝时期, 受到两汉时期的影响, 尽管此时的朝局虽然动荡, 少数民族对中原的战争不断, 也有少数民族统治中原, 但是统治阶级对 于书法的重视程度依然不减。随着士族阶级的兴盛, 士族阶层对于书法 极为推崇, 家学庭训对书法的影响极大, 也因此出了如王羲之、王献之等 书法大家。

隋唐五代时期可以说是书法教育最为鼎盛的时期。隋朝对于书法教育 的重视程度远胜于前朝, 《隋书》中记载:

统国子、太学、四门、书、算学, 各置博士、国子、太学、四门各五 人, 书、算各二人。学生国子一百四十人, 太学、四门各三百六十人, 书四 十人、算八十人。

由此可知, 在隋朝的官学中, 已经有了书法专业的老师。

唐代的书法教育继续延续了隋代的做法, 加之唐朝统治者对于书法 的爱好与热衷, 因此对书法教育更加重视, 不仅在全国官学中设有书法 课程, 甚至还给了书法老师一定的官职, 在很大程度上提高了书法老师 的地位。对于学生所学有了年限的规定。不仅如此, 对于学生日长作业也 有了 “学书, 日纸一幅” 的具体要求。书法成为了唐代的重要教学内容。 科举制也是推动唐朝书法教育走向高峰的重要原因, 在唐朝的分科取士中 有一科为 “明书” 也称书科, 考试内容就是文字学和书法。对于六品以下 官员的选拔中也要先进行书法的考核, 在进行其他的考核, 如果不能一一 考察, 那么就会仅凭书、判而选的现象。不仅如此, 唐代还随时设有制举之 科, 以此来随时选拔善书者。正因为在唐朝善书者可以通过走仕途之路改 变自己的命运, 也使得更多的读书人在书法上下功夫, 因此唐朝也是书法 人才辈出的年代。

宋朝依然是一个重视书法教育的年代, 在科举考试中, 书法仍然作为 一个单独的科目出现, 在南宋时期, 由于统治者对于书法的热爱, 甚至于有 皇帝亲自教授书法, 宋徽宗时期虽然宋徽宗是一个懦弱无能的皇帝, 但不 能因此否认他在诗书画上的造诣, 宋徽宗为了弘扬书法, 还专门设立“书艺 所”《宋史》记载:

书学生, 习管、隶、草三体, 明说文、字说、尔雅、博雅、方言, 兼通 论语、孟子义, 愿占大经者听, 笙以古文、大小二策为法, 隶以二王、欧、 虞、颜、柳真行为法, 草以章草、张芝九体为法。考书之等, 以方圆肥瘦适 中, 锋藏面劲, 气清韵古, 老而不俗为上: 方而有圆笔, 圆而有方意, 瘦而不 枯, 肥而不浊, 各得一体者为中; 方而不能圆, 肥而不能瘦, 模仿故人笔画不
得其意, 而均齐可观为下 ${ }^{[4]}$ 。

由此可以看出宋代对于书法专业教育要求之细、之严, 这也是前所未 有的。

元朝为少数民族所创立, 对于书法教育重视程度明显不如前朝, 虽然 在元朝中后期也开始重视中原文化, 重视书法, 也出现了赵孟煩之类的书 法大家, 但是相比较而言, 书法教育并不受到重视。

明清时期, 书法教育再次受到重视, 书法教育贯穿整个教育始终, 统治 阶级对于字体的控制也是前所未有的，“馆阁体” 成为了当时科举的规定 书体, 也因此在很大程度上限制了书法的发展。这并没有影响到明清的书 法教育的发展, 统治者对于书法的要求还是很高的, 例如对于国子监生的 书法练习有着明确的规定。

清代虽然是少数民族统治时期, 但是对于书法的要求并不比前朝低, 在科举取士之中 “馆阁体” 仍然大行其道, 因此清代从书法的基础教育便 以工整、秀美为基础, 杜绝偏、怪字体的出现。不仅如此, 在选官之后, 对 于官吏的书法考察也是丝毫不松解的, 书法好的官员会因此得到升迁, 而 书法不好的官员会被降级罚俸。清代书法家学也发展到高峰, 书法家们对 于其子女、弟兄的书法学习也是十分严格的, 因此在清朝书法史上父子、 兄弟同为书法家的现象十分普遍。在康乾两代, 经济的繁荣推动了文化的 繁荣, 书院教育蔚然成风, 从南到北各大书院均请当时著名的书法家进行 讲学。这一切都使得人们对于书法学习的热情空前的高涨。也在很大程度 上推动了清代书法教育的发展。

书法教育从来不会是单独存在的, 他是为统治阶级服务的工具, 随着 统治阶级的意志而变化, 在中国古代的书法教育中, 无论是只作为教学辅 助工具还是发展到后来成为一项专门的艺术, 书法教学通常是以将识字、 写字为一体, 以法帖为临摹范本, 加上每日固定的练习数量以及不断提高 自身的文化程度从而达到相应的要求。对于今天的书法教学来讲, 这是十 分可取的。

\section{[参考文献]}

[1]郭沫若.殷墟萃编・考释[M].北京:科学出版社,1956:733.

[2]丛文俊.中国书法史先秦・秦代卷 [M].江苏: 江苏教育出版 社,2012:403.

[3]华人德.中国书法史・两汉卷[M].江苏: 江苏教育出版社,2012:23. [4]脱脱.宋史(元)[Z].北京:中华书局,1977:58.

\section{作者简介：}

周晴(1991--),女,汉族,山东济南人,艺术硕士,研究方向: 书法方向。 